\section{RMD Open}

Rheumatic \&

Musculoskeletal Diseases

\title{
Tophus resolution with pegloticase: a prospective dual-energy CT study
}

\author{
Elizabeth G Araujo, ${ }^{1}$ Sara Bayat, ${ }^{1}$ Christina Petsch, ${ }^{1}$ Matthias Englbrecht, ${ }^{1}$ \\ Francesca Faustini, ${ }^{1}$ Arnd Kleyer, ${ }^{1}$ Axel J Hueber, ${ }^{1}$ Alexander Cavallaro, ${ }^{2}$ \\ Michael Lell, ${ }^{2}$ Nicola Dalbeth, ${ }^{3}$ Bernhard Manger, ${ }^{1}$ Georg Schett, ${ }^{1}$ Juergen Rech ${ }^{1}$
}

To cite: Araujo EG, Bayat S, Petsch C, et al. Tophus resolution with pegloticase: a prospective dual-energy CT study. RMD Open 2015;1: e000075. doi:10.1136/ rmdopen-2015-000075

- Prepublication history for this paper is available online. To view these files please visit the journal online (http://dx.doi.org/10.1136/ rmdopen-2015-000075)

Received 26 January 2015 Revised 9 March 2015 Accepted 13 March 2015

\section{CrossMark}

${ }^{1}$ Department of Internal Medicine 3 and Institute for Clinical Immunology, University of ErlangenNuremberg, Erlangen, Germany

${ }^{2}$ Department of Radiology, University of ErlangenNuremberg, Erlangen, Germany

${ }^{3}$ Bone and Joint Research Group, Department of Medicine, University of Auckland, Auckland, New Zealand

\section{Correspondence to} Dr Juergen Rech; juergen.rech@uk-erlangen.de

\section{ABSTRACT}

Objective: To investigate the effect of intensive lowering of serum uric acid (SUA) levels by pegloticase on the resolution of tophi in patients with refractory gout.

Methods: Descriptive study in patients with refractory gout receiving pegloticase treatment. SUA levels were measured before and after each infusion. Dual-energy CT (DECT) scans were taken from all patients before the first infusion and after the last infusion. Computerised tophus volumes were calculated for the baseline and follow-up assessments and compared with each other.

Results: 10 patients with refractory gout and baseline mean SUA level of $8.1 \mathrm{mg} / \mathrm{dL}$ were enrolled. Patients were treated for a mean of 13.3 weeks. Pegloticase effectively reduced tophi in all patients showing a decrease in volume by $71.4 \%$. Responders, showing reduction of SUA level below $6 \mathrm{mg} / \mathrm{dL}$ during at least $80 \%$ of the treatment time, were virtually cleared from tophi $(-94.8 \%)$. Dependent on their anatomical localisation, resolution of tophi showed different dynamics, with articular tophi showing fast, and tendon tophi slow, resolution.

Conclusions: Tophi are highly sensitive to pegloticase treatment, particularly when located at articular sites. Debulking of disease and a tophus-free state can be reached within a few months of pegloticase treatment. DECT allows for comprehensively assessing tophus burden and monitoring treatment responses.

\section{INTRODUCTION}

Gout is characterised by the deposition of monosodium urate (MSU) crystals. ${ }^{1}$ Dense deposits of MSU crystals are also known as tophi. ${ }^{2}$ Recent data have shown that tophi form by densely packaging MSU crystals inside aggregated neutrophil extracellular traps (NETs). ${ }^{3}$ While tophus formation allows for containment and resolution of inflammation, the large amounts of MSU crystals harboured in tophi bear the risk of bouts of inflammation, as MSU crystals are not cleared but only contained by these structures.

Tophi are reversible lesions. Changes of uric acid level may impact tophus size with regression of lesion, if uric acid level falls. ${ }^{5}$

\section{Key messages}

What is already known on this subject?

Dual-energy CT (DECT) gives insight in the understanding of tophus size and resolution over time.

What might this study add?

Pegloticase, even if used for a limited period of time, causes significant reduction of tophus burden.

However, the dynamics of tophus resolution are poorly defined, as appropriate techniques to quantify tophus burden are relatively new and not widely applied to date. Dual-energy CT (DECT) scan allows identification and quantification of tophi in the musculoskeletal tissues. ${ }^{6}{ }^{7}$ Hence, DECT may represent an ideal tool to assess the dynamics of tophus formation and resolution of gout. ${ }^{8}$

Pegloticase, a pegylated mammalian recombinant uricase, is currently the most powerful uric acid-lowering therapy ${ }^{9-12}$ and therefore provides a possibility to investigate the resolution of tophi in humans. We therefore set up a prospective observational DECT study to investigate the regression of tophi after refractory gout patients were exposed to pegloticase.

\section{METHODS}

\section{Patient characteristics and study design}

This prospective observational study included patients with a diagnosis of gout, who, despite conventional uric acid-lowering therapy, continued to have flares (defined as swelling and/or musculoskeletal pain) and revealed tophus deposits on the DECT examination. Pegloticase $8 \mathrm{mg}$ was administered intravenously every 2 weeks, after all other uric acidlowering therapy was stopped. Infusions were discontinued if patients achieved clinical remission (defined as sustained serum uric acid (SUA) below $6.0 \mathrm{mg} / \mathrm{dL}$, absence of flares for at least 30 days and complete 
resolution of visible tophi) or if patients developed an infusion reaction ascribed to pegloticase. All patients provided written informed consent agreeing to participate in the study, which was approved by our institutional review board.

\section{Demographic and disease-specific parameters}

Demographic characteristics were recorded at baseline. The presence of renal insufficiency, hypertension, diabetes mellitus, hyperlipidaemia and atherosclerotic disease was documented. In addition, use of medications that could interfere with SUA level, such as diuretics, aspirin, ACE inhibitors, angiotensin blockers and $\beta$-blockers, was assessed. SUA was measured immediately before each infusion, as well as directly after the infusion. Serum creatinine, C reactive protein and erythrocyte sedimentation rate were also assessed.

\section{DECT scan}

Patients underwent DECT examination of hands and feet prior to receiving the first pegloticase infusion and after the last infusion. Images were generated by a second-generation 128-slice dual source CT system (Definition Flash; Siemens Healthcare) with two X-ray tubes operating at 80 and $140 \mathrm{kV}$. Syngo Dual Energy software (CT Workplace VA44, Siemens Healthcare) was used to process these data and allowed for volume calculation. Images of hands/wrists and feet/ankles were evaluated by two independent readers (SB and $\mathrm{CP}$ ) who were blinded to the clinical data. Additionally, the volume of tophi was calculated automatically after artefacts were removed. ${ }^{13}$

\section{Statistical analysis}

Descriptive statistics were used to outline demographic and clinical features for the total sample as well as for stratified subgroups of patients considered responders, and for those considered partial responders. Results on parametric data include sample size and arithmetic means \pm SDs. Owing to the limited size of the exploratory sample, data are also presented as median (IQR) in the text. Missing values were not imputed to preserve the original information of the data. All statistical analyses were computed using IBM SPSS Statistics V.21 software.

\section{RESULTS}

\section{Patients}

Ten patients ( 7 males and 3 females) were enrolled in this study. Mean $( \pm \mathrm{SD})$ age of the patients was 58.2 $( \pm 10.29)$ and mean $( \pm \mathrm{SD})$ duration of disease was 55.2 $( \pm 45.9)$ months. Five patients had renal insufficiency, eight had hypertension, two had diabetes mellitus and three had atherosclerotic disease. Eight patients were overweight, mean BMI was $27.82( \pm 7.52)$. Pretreatment SUA level $($ mean \pm SD) was $8.08 \pm 2.34 \mathrm{mg} / \mathrm{dL}$ and serum creatinine $($ mean $\pm \mathrm{SD})$ was $1.26 \pm 0.56 \mathrm{mg} / \mathrm{dL}$. Patients received a mean \pm SD of $5.8 \pm 3.99$ pegloticase infusions and were treated for a mean of $13.32 \pm 9.70$ weeks (responders $17.25 \pm 10.38$ weeks; partial responders 9.40 \pm 8.08 weeks). Five patients were considered responders, as their SUA level remained below saturation level $(<6 \mathrm{mg} / \mathrm{dL})$ for more than $80 \%$ of the treatment period. The five remaining patients were considered partial responders, losing treatment efficacy due to immunogenicity to pegloticase and development of infusion reactions. All infusion reactions were mild and resolved after glucocorticoid administration.

\section{DECT volumes and scores}

Pre-treatment DECT scans were obtained from hands and feet in seven patients $(70 \%)$ and from feet alone in three $(30 \%)$. DECT scan was performed either on the day of the first infusion or up to 4 months before. Owing to unavailability of the medication there was a delay between the first DECT images and the first pegloticase infusion in five patients. Follow-up images were taken of the hands and feet in eight patients, and, in the remaining two patients, of the feet only. Post-treatment images were obtained as early as on the day of the last infusion and as far ahead as 5 months after the end of therapy in one single patient.

Mean \pm SD DECT tophus volume before therapy was $9.15 \mathrm{~cm}^{3} \pm 13.26$ for all patients (median and IQR: 4.31 and $12.39 \mathrm{~cm}^{3}$ ). After therapy, mean \pm SD DECT tophus volume was $1.89 \mathrm{~cm}^{3} \pm 2.86$ for all patients (median and IQR: 0.19 and $\left.5.46 \mathrm{~cm}^{3}\right)$. It was reduced to very small lesions in the responders (mean \pm SD:0.12 $\mathrm{cm}^{3} \pm 0.11$, median and IQR: 0.17 and $0.22 \mathrm{~cm}^{3}$ ) showing a $94.76 \%$ volume reduction. Also, in partial responders, tophus volume was reduced, although an incomplete resolution of lesions with a $47.97 \%$ reduction was found. Mean \pm SD remaining tophus volume in partial responders was 3.67 $\pm 3.25 \mathrm{~cm}^{3}$ and the median (IQR) was $5.33(6.24) \mathrm{cm}^{3}$. Table 1 shows patients' characteristics and figure 1 indicates individual volume responses for patients considered responders and patients considered partial responders (a), as well as the SUA levels for each individual patient after the initial four infusions with pegloticase (b), percentage of volume change for each individual patient (c), and relation between tophus volume reduction and SUA level reduction (d). Figure 2 shows three-dimensional DECT images of a patient from the responder group, as well as a patient from the partial responder group, before and after therapy.

Regarding pattern of resolution of tophi, we observed that deposits resolved in the articular areas first and persisted longer in bradytrophic tissues, such as the tendons, as is clearly shown in figure $2 \mathrm{D}$, exemplifying a patient who received only two infusions of pegloticase after experiencing infusion reactions. Uric acid level fell only moderately from 6.3 to $5.6 \mathrm{mg} / \mathrm{dL}$. Still, follow-up DECT scan showed substantial reduction of MSU deposits in the joints, while large bulky tophi persisted almost unchanged around the Achilles tendon. 


\begin{tabular}{|c|c|c|c|c|c|c|c|c|c|c|}
\hline Patient & Gender & Age & Reason to enrol & $\begin{array}{l}\text { SUA level } \\
\text { (mg/dL) }\end{array}$ & $\begin{array}{l}\text { Previous uric } \\
\text { acid-lowering } \\
\text { therapy }\end{array}$ & $\begin{array}{l}\text { Number of } \\
\text { pegloticase } \\
\text { infusions }\end{array}$ & $\begin{array}{l}\text { Reason to } \\
\text { discontinue } \\
\text { therapy }\end{array}$ & $\begin{array}{l}\text { Initial } \\
\text { volume } \\
\left(\mathrm{cm}^{3}\right)\end{array}$ & $\begin{array}{l}\text { Time between } \\
\text { DECTs (days) }\end{array}$ & $\begin{array}{l}\text { Volume } \\
\text { reduction (\%) }\end{array}$ \\
\hline \multicolumn{11}{|c|}{ Responders } \\
\hline 1 & $\mathrm{~F}$ & 55 & Frequent flares & 11.2 & Allopurinol & 12 & Clinical remission & 0.33 & 195 & 96.96 \\
\hline 2 & M & 43 & Tophaceous gout & 7.7 & Allopurinol & 14 & Clinical remission & 40.79 & 220 & 99.58 \\
\hline 3 & M & 67 & $\begin{array}{l}\text { Frequent flares and } \\
\text { tophaceous gout }\end{array}$ & 5.3 & Allopurinol & 5 & Clinical remission & 8.3 & 298 & 97.10 \\
\hline 4 & $\mathrm{~F}$ & 75 & Frequent flares & 10.2 & Allopurinol & 5 & Clinical remission & 0.03 & 151 & 100 \\
\hline 5 & M & 59 & $\begin{array}{l}\text { Frequent flares and } \\
\text { tophaceous gout }\end{array}$ & 4.7 & Benzbromarone & 4 & Clinical remission & 1.06 & 125 & 80.18 \\
\hline \multicolumn{11}{|c|}{ Partial responders } \\
\hline 1 & M & 55 & Tophaceous gout & 11.4 & Febuxostat & 4 & $\begin{array}{l}\text { Allergic reaction, } \\
\text { persistent } \\
\text { hyperuricaemia }\end{array}$ & 7.56 & 123 & 29.49 \\
\hline 2 & M & 43 & Tophaceous gout & 6.9 & Febuxostat & 5 & $\begin{array}{l}\text { Allergic reaction, } \\
\text { persistent } \\
\text { hyperuricaemia }\end{array}$ & 0.77 & 312 & 81.81 \\
\hline 3 & $\mathrm{~F}$ & 67 & Tophaceous gout & 6.3 & Febuxostat & 2 & $\begin{array}{l}\text { Allergic reaction, } \\
\text { persistent } \\
\text { hyperuricaemia }\end{array}$ & 23.35 & 112 & 73.10 \\
\hline 4 & M & 55 & Tophaceous gout & 8.5 & Allopurinol & 2 & $\begin{array}{l}\text { Allergic reaction, } \\
\text { persistent } \\
\text { hyperuricaemia }\end{array}$ & 9.13 & 116 & 29.13 \\
\hline 5 & M & 63 & $\begin{array}{l}\text { Frequent flares and } \\
\text { tophaceous gout }\end{array}$ & 8.6 & Allopurinol & 5 & $\begin{array}{l}\text { Allergic reaction, } \\
\text { persistent } \\
\text { hyperuricaemia }\end{array}$ & 0.19 & 115 & 26.31 \\
\hline
\end{tabular}




\section{DISCUSSION}

On the basis of the dense packaging of MSU crystals, tophi give a characteristic signal in the DECT scan, ${ }^{14-17}$ which allows for visualising them at sites that are not accessible by mere inspection of the joints. ${ }^{6}{ }^{7}$ We show that profound lowering of uric acid levels by pegloticase effectively and rapidly resolves tophi in the musculoskeletal tissues of patients with advanced gout.

Previous data showed that lowering of SUA levels is associated with the regression of clinically visible tophi and that regression of tophi depends on the extent of decrease of uric acid level. ${ }^{5}$ However, a comprehensive and quantitative assessment of tophus burden in the body and its responsiveness to treatment has not been undertaken so far, since previous investigations were confined to clinically visible tophi. This prospective DECT study showed that (1) sustained lowering of SUA levels virtually cleared patients from all tophi within a few months. Furthermore, (2) even transient lowering of SUA level in patients in whom immune reactions against pegloticase prevented further treatment (partial responders) allowed for cutting down tophus volume by roughly $50 \%$, suggesting that tophi are highly dynamic structures that lose their mass as soon as uric acid levels are low. Finally, (3) the speed of resolution of tophi depends on their anatomical localisation. Deposits at bradytrophic tissues such as tendons showed substantially slower resolution compared with deposits in the joints.

Here, pegloticase was used as an instrument to tackle the dynamics of reversibility of uric acid deposits in
A

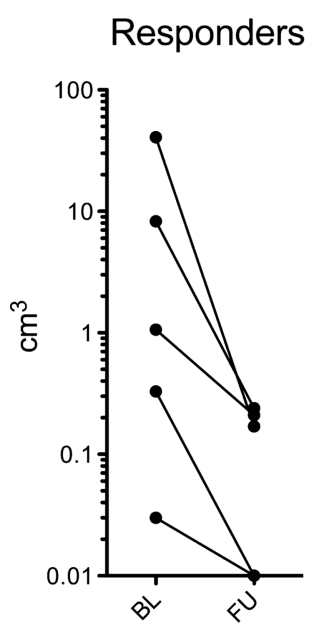

Partial

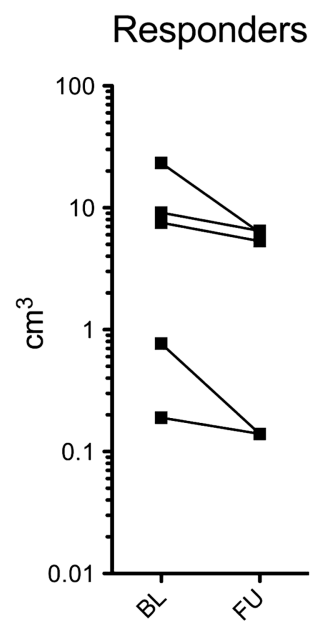

C Dynamics of tophus volume change

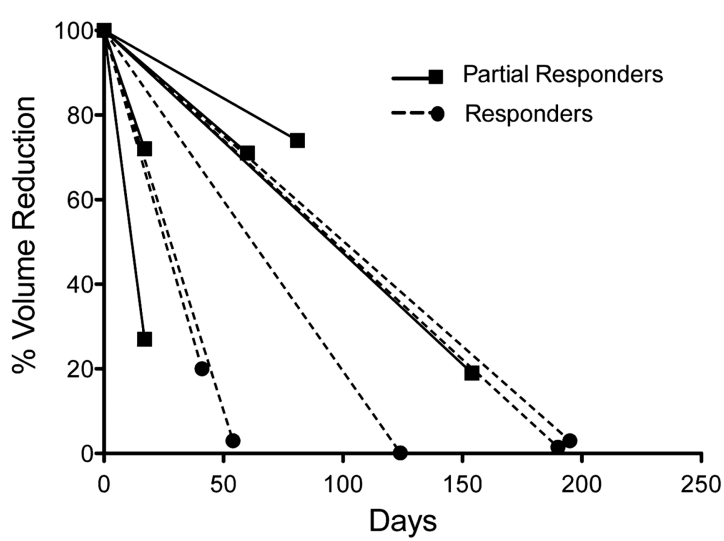

B

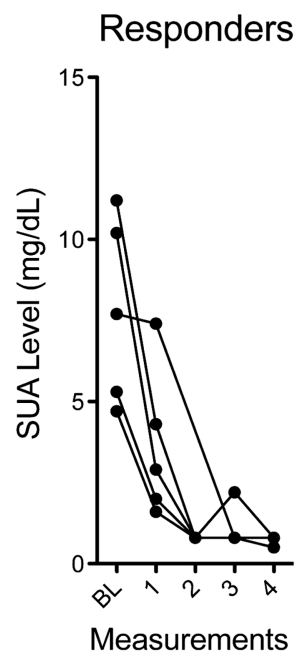

Partial

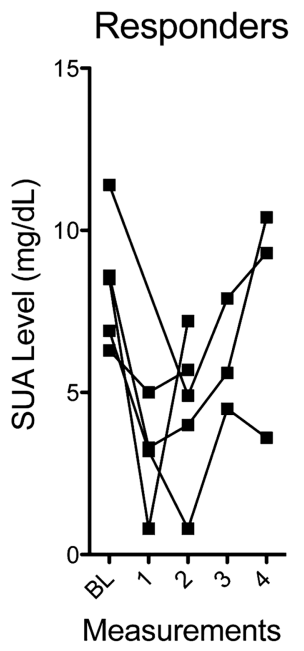

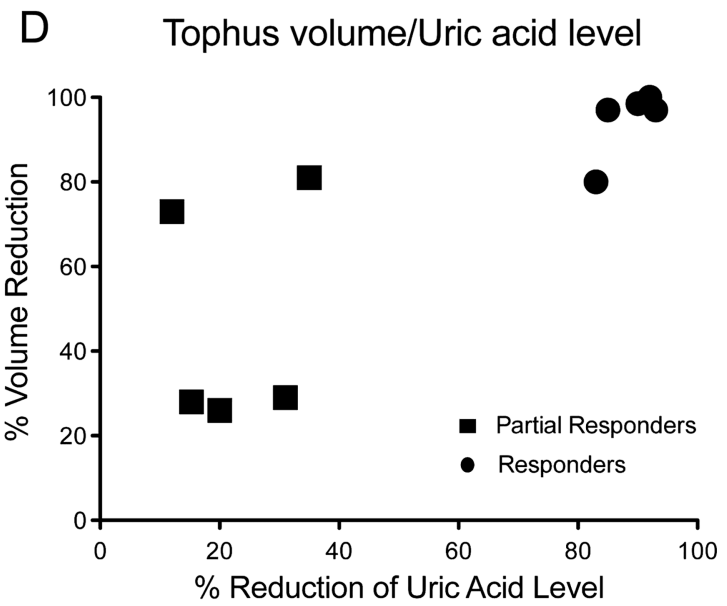

Figure 1 Changes in tophus volumes after pegloticase treatment. (A) Changes of dual-energy CT (DECT)-based tophus volumes $\left(\mathrm{cm}^{3}\right)$ from each individual patient at baseline $(\mathrm{BL})$ before treatment and at follow-up after treatment. Patients were divided into two groups: responders (circles) and partial responders (squares) based on serum uric acid (SUA) response. Note the logarithmic scales. (B) SUA levels at BL and after the first four infusions with pegloticase. Two patients in the partial responder's group only received two infusions, hence only two SUA levels are demonstrated in the graph. (C) Dynamics of tophus volume reduction in responders (circles, dashed lines) and partial responders (squares, solid lines) dependent on the duration of pegloticase exposure. (D) Relation between tophus volume reduction (in \%) and SUA level reduction (in \%) in responders (circles) and partial responders (squares). 


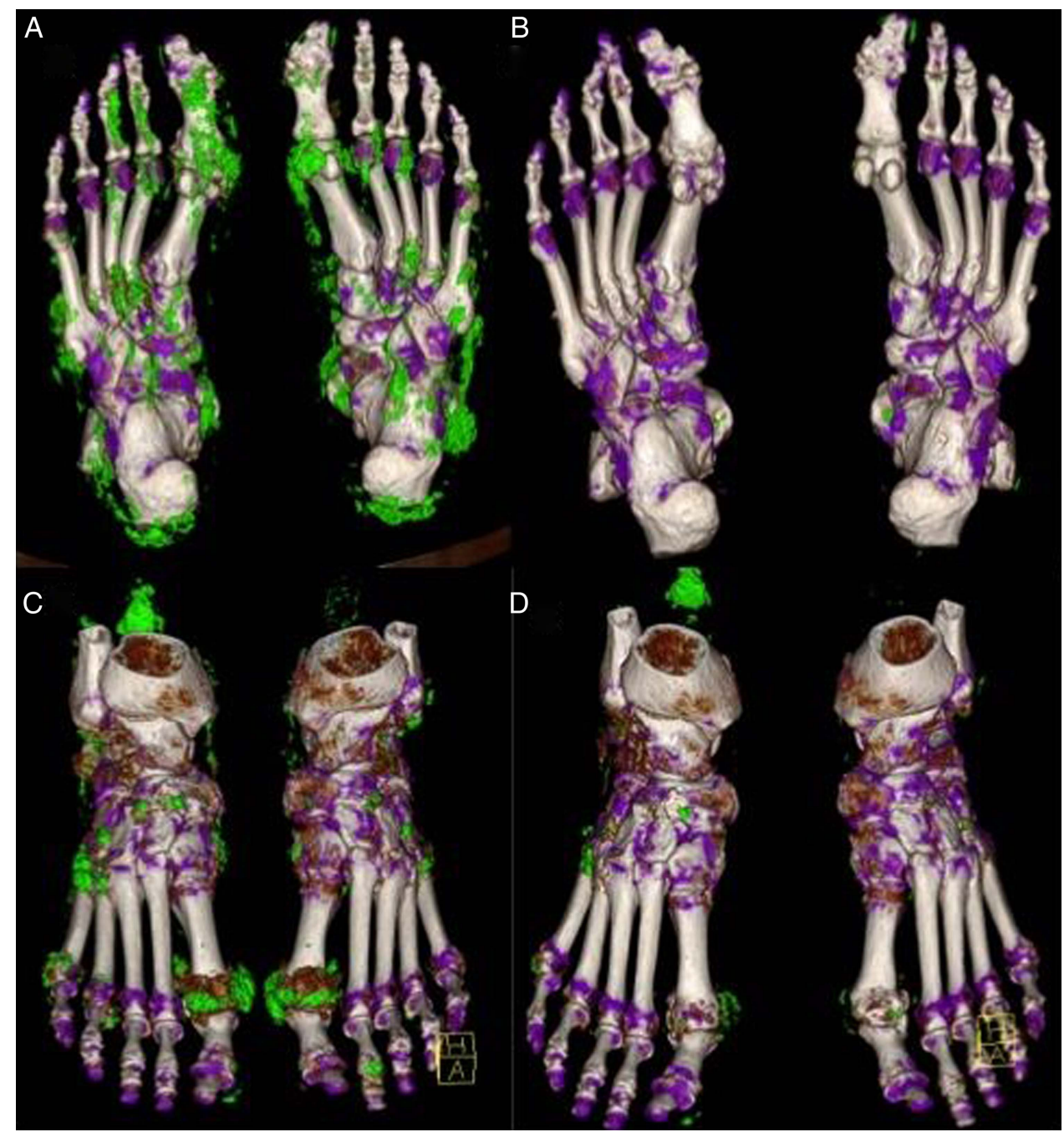

Figure 2 Resolution of tophi after exposure to pegloticase. Three-dimensional dual-energy CT images from a chronic tophaceous gout patient responding to pegloticase ( $A$ and $B$ ) and from a patient showing partial response $(C$ and $D)$. Multiple tophi can be found in the feet ( $A$ and $C$ ) prior to pegloticase treatment (green pixels). Images obtained after treatment showing almost complete resolution of deposits in the feet of the responder patient $(B)$ and significant reduction in the feet of the partial responder (D).

vivo. Our data suggest that even large tophi can resolve when patients are exposed to highly potent uric acidlowering therapy. DECT technology is an excellent tool to comprehensively assess tophus burden and to longitudinally monitor treatment response. The data also suggest that a 'tophus-free' state may become a measureable and reachable treatment target even in patients with severe manifestations of gout when effective treatments such as pegloticase are used. Recent insights in the prediction of infusion reactions to pegloticase will further improve the safety of its use in patients with severe gout. ${ }^{18}$

Acknowledgements The authors would like to thank Patrizia Sternard, MD, Jochen Wacker, MD, and Anne Dieterle, MD, for referring patients to this study. This study was supported by the Deutsche Forschungsgemeinschaft (SPP1468-Immunebone), the Bundesministerium für Bildung und Forschung (BMBF; project Metarthros), the Marie Curie project Osteoimmune, the Team and Masterswitch projects of the European Union and the IMI funded project BTCure. This publication will be used as doctoral thesis for Elizabeth Guilhon de Araujo at the Friedrich-Alexander University Erlangen-Nuremberg, Erlangen, Germany.

Contributors EGA, SB, CP, FF, AK, AH, AC, ML collected and analysed the data. ME performed the statistical analyses. EGA, ND, BM, GS, JR designed the study and wrote the manuscript.

Competing interests None.

Ethics approval Local Ethics Committee.

Provenance and peer review Not commissioned; externally peer reviewed.

Data sharing statement No additional data are available.

Open Access This is an Open Access article distributed in accordance with the Creative Commons Attribution Non Commercial (CC BY-NC 4.0) license, which permits others to distribute, remix, adapt, build upon this work noncommercially, and license their derivative works on different terms, provided the original work is properly cited and the use is non-commercial. See: http:// creativecommons.org/licenses/by-nc/4.0/ 


\section{REFERENCES}

1. Busso N, So A. Mechanisms of inflammation in gout. Arthritis Res Ther 2010;12:206.

2. Dalbeth N, Pool B, Gamble GD, et al. Cellular characterization of the gouty tophus: a quantitative analysis. Arthritis Rheum 2010;62:1549-56.

3. Schauer C, Janko C, Munoz LE, et al. Aggregated neutrophil extracellular traps limit inflammation by degrading cytokines and chemokines. Nat Med 2014;20:511-17.

4. Schorn C, Janko C, Krenn V, et al. Bonding the foe-NETting neutrophils immobilize the pro-inflammatory monosodium urate crystals. Front Immunol 2012;3:376.

5. Perez-Ruiz F, Calabozo M, Pijoan Jl, et al. Effect of urate-lowering therapy on the velocity of size reduction of tophi in chronic gout. Arthritis Rheum 2002;47:356-60.

6. Manger B, Lell M, Wacker J, et al. Detection of periarticular urate deposits with dual energy CT in patients with acute gouty arthritis. Ann Rheum Dis 2012;71:470-2.

7. Choi HK, Al-Arfaj AM, Eftekhari A, et al. Dual energy computed tomography in tophaceous gout. Ann Rheum Dis 2009;68:1609-12.

8. Dalbeth N, Aati O, Kalluru R, et al. Relationship between structural joint damage and urate deposition in gout: a plain radiography and dual-energy CT study. Ann Rheum Dis 2015;74:1030-6.

9. Sundy JS, Baraf HS, Yood RA, et al. Efficacy and tolerability of pegloticase for the treatment of chronic gout in patients refractory to conventional treatment: two randomized controlled trials. JAMA 2011;306:711-20.
10. Baraf HS, Becker MA, Gutierrez-Urena SR, et al. Tophus burden reduction with pegloticase: results from phase 3 randomized trials and open-label extension in patients with chronic gout refractory to conventional therapy. Arthritis Res Ther 2013;15: R137.

11. Becker MA, Baraf HS, Yood RA, et al. Long-term safety of pegloticase in chronic gout refractory to conventional treatment. Ann Rheum Dis 2013;72:1469-74.

12. Crittenden DB, Pillinger MH. New therapies for gout. Annu Rev Med 2013;64:325-37.

13. Mallinson PI, Coupal T, Reisinger C, et al. Artifacts in dual-energy CT gout protocol: a review of 50 suspected cases with an artifact identification guide. AJR Am J Roentgenol 2014;203:103-9.

14. Melzer R, Pauli C, Treumann T, et al. Gout tophus detection-a comparison of dual-energy CT (DECT) and histology. Semin Arthritis Rheum 2014;43:662-5.

15. Bongartz T, Glazebrook KN, Kavros SJ, et al. Dual-energy CT for the diagnosis of gout: an accuracy and diagnostic yield study. Ann Rheum Dis 2015;74:1072-7.

16. Choi HK, Burns LC, Shojania K, et al. Dual energy CT in gout: a prospective validation study. Ann Rheum Dis 2012;71:1466-71.

17. Girish G, Glazebrook KN, Jacobson JA. Advanced imaging in gout. Am J Roentgenol 2013;201:515-25.

18. Baraf HS, Yood RA, Ottery FD, et al. Infusion-related reactions with pegloticase, a recombinant uricase for the treatment of chronic gout refractory to conventional therapy. J Clin Rheumatol 2014;20:427-32. 